\title{
RESEARCH
}

Open Access

\section{Upregulation of Apo/8 by Epothilone D facilitates the neuronal relay of transplanted NSCs in spinal cord injury}

Weiwei Xue ${ }^{1 \dagger}$, Haipeng Zhang ${ }^{1,2 \dagger}$, Yongheng Fan ${ }^{1,2}$, Zhifeng Xiao ${ }^{1}$, Yannan Zhao ${ }^{1}$, Weiyuan Liu ${ }^{1,2}$, Bai Xu', Yanyun Yin ${ }^{1}$, Bing Chen ${ }^{1}$, Jiayin $\mathrm{Li}^{1}, \mathrm{Yi} \mathrm{Cui}^{3}, \mathrm{Ya} \mathrm{Shi}^{1}$ and Jianwu Dai ${ }^{1,4^{*}}$

\begin{abstract}
Background: Microtubule-stabilizing agents have been demonstrated to modulate axonal sprouting during neuronal disease. One such agent, Epothilone D, has been used to treat spinal cord injury (SCI) by promoting axonal sprouting at the lesion site after SCl. However, the role of Epothilone D in the differentiation of neural stem cells (NSCs) in SCl repair is unknown. In the present study, we mainly explored the effects and mechanisms of Epothilone D on the neuronal differentiation of NSCs and revealed a potential new SCI treatment.

Methods: In vitro differentiation assays, western blotting, and quantitative real-time polymerase chain reaction were used to detect the effects of Epothilone D on NSC differentiation. Retrograde tracing using a pseudotyped rabies virus was then used to detect neuronal circuit construction. RNA sequencing (RNA-Seq) was valuable for exploring the target gene involved in the neuronal differentiation stimulated by Epothilone D. In addition, lentivirus-induced overexpression and RNA interference technology were applied to demonstrate the function of the target gene. Last, an Apol8-NSC-linear ordered collagen scaffold (LOCS) graft was prepared to treat a mouse model of SCI, and functional and electrophysiological evaluations were performed.

Results: We first revealed that Epothilone D promoted the neuronal differentiation of cultured NSCs and facilitated neuronal relay formation in the injured site after SCl. Furthermore, the RNA-Seq results demonstrated that Apo/8 was upregulated during Epothilone D-induced neuronal relay formation. Lentivirus-mediated Apol8 overexpression in NSCS (Apol8-NSCs) promoted NSC differentiation toward neurons, and an Apol8 interference assay showed that Apol8 had a role in promoting neuronal differentiation under the induction of Epothilone D. Last, Apo/8-NSC transplantation with LOCS promoted the neuronal differentiation of transplanted NSCs in the lesion site as well as synapse formation, thus improving the motor function of mice with complete spinal cord transection.
\end{abstract}

\footnotetext{
* Correspondence: jwdai@genetics.ac.cn

'Weiwei Xue and Haipeng Zhang contributed equally to this work.

'State Key Laboratory of Molecular Developmental Biology, Institute of

Genetics and Developmental Biology, Chinese Academy of Sciences, Beijing

100101, China

${ }^{4}$ Key Laboratory for Nano-Bio Interface Research, Division of

Nanobiomedicine, Suzhou Institute of Nano-Tech and Nano-Bionics, Chinese

Academy of Sciences, Suzhou 215123, China

Full list of author information is available at the end of the article
}

\section{$\triangle B M C$}

C C The Author(s). 2021 Open Access This article is licensed under a Creative Commons Attribution 4.0 International License, which permits use, sharing, adaptation, distribution and reproduction in any medium or format, as long as you give appropriate credit to the original author(s) and the source, provide a link to the Creative Commons licence, and indicate if changes were made. The images or other third party material in this article are included in the article's Creative Commons licence, unless indicated otherwise in a credit line to the material. If material is not included in the article's Creative Commons licence and your intended use is not permitted by statutory regulation or exceeds the permitted use, you will need to obtain permission directly from the copyright holder. To view a copy of this licence, visit http://creativecommons.org/licenses/by/4.0/ The Creative Commons Public Domain Dedication waiver (http://creativecommons.org/publicdomain/zero/1.0/) applies to the data made available in this article, unless otherwise stated in a credit line to the data. 
Conclusions: Epothilone D can promote the neuronal differentiation of NSCs by upregulating Apo/8, which may provide a promising therapeutic target for $\mathrm{SCl}$ repair.

Keywords: Epothilone D, Apol8, Neuronal differentiation, Neural stem cell, Spinal cord injury

\section{Background}

Spinal cord injury (SCI) is a serious condition of the central nervous system (CNS), and SCI repair is a great clinical challenge. After SCI, cell death, ischemia, excitotoxicity, edema, immune reaction, and other phenomena occur at the injured site, and a series of pathological reactions form an inhibitory microenvironment that blocks nerve regeneration [1, 2]. Myelin-associated inhibitors, including Nogo, myelin-associated glycoprotein, and oligodendrocyte myelin glycoprotein, inhibit CNS axon regeneration and sprouting [3]. After SCI, a large number of neurons are lost and axons gradually deteriorate [4]. SCI leads to permanent functional defects because of the loss of neurons and axons, while the spontaneous regeneration of neurons and axons is limited [5]. Functional connections between neurons are lost, nerve impulse transmission terminates, and a large number of astrocytes around the damaged area are activated, which forms a physical barrier or glial scar, in the damaged area, seriously hindering axonal regrowth and the reconstruction of new neural circuits [6].

Neural stem cells (NSCs) play an important role in the nervous system and have attracted much attention in SCI studies because of their ability to differentiate into neurons and glial cells $[7,8]$. NSC transplantation is not only a simple replacement of lost nerve cells in the damaged area; NSCs can also secret nutritional factors, promote cell survival, and stimulate bridge formation between axons and the host to promote functional recovery [9-11]. NSC transplantation can compensate for the loss of neurons and can provide seed cells for clinical SCI treatment, which is considered to be a promising strategy for the treatment of severe SCI. However, many studies have shown that the vast majority of transplanted NSCs differentiate into astrocytes in the SCI inhibitory microenvironment but cannot differentiate into neurons [12-14]. Promoting neuronal differentiation of NSCs may be effective in SCI repair.

Many growth factors, antibodies, and chemicals can benefit the neuronal differentiation of NSCs. However, effective differentiation of NSCs has not been fully resolved [15]. NSC differentiation depends, in part, on cell cycle regulation, and cell fate can be determined by the distribution of genetic material through spindle microtubule stretching [16]. In recent years, some anticancer drugs that stabilize microtubules have been used in the treatment of SCI. Our recent study found that cetuximab, an anticancer drug, antagonized the SCI inhibitory microenvironment to promote neuronal differentiation of NSCs through blocking of the EGFR-ERK pathway [17]. In addition, the anticancer drug, paclitaxel, can promote the growth of neuronal axons by stabilizing microtubules. A low dose of paclitaxel can promote the neuronal differentiation of NSCs and inhibit their differentiation into astrocytes by stabilizing microtubules, which promotes the recovery of motor function after SCI in rodents [18-20]. However, paclitaxel administered after SCI can be toxic to cells and tends to diffuse, making it difficult to control the concentration of the drug. In recent years, Ruschel et al. have shown that Epothilone B stabilizes microtubules, can reduce scarring, and stimulates axonal regeneration, thereby restoring motor function after SCI [21, 22]. Epothilone D, a substitute for Epothilone B, has greater blood-brain barrier permeability and displays better bioavailability and effectiveness in rodent CNS disease models. Microtubule-stabilizing drugs are effective in the treatment of $\mathrm{SCI}$ and neurodegenerative diseases, such as Alzheimer's disease [23]. Compared with paclitaxel, Epothilone D is simple in structure and is more conducive to chemical synthesis. It also has better water solubility and lower cytotoxicity and crosses the blood-brain barrier more easily [24]. Epothilone D can improve hind limb control in adult rats with contusion SCI, can reduce inhibitory fibrotic scar tissue in damaged areas, and can restore nerve innervation in the lumbar spine [25]. Epothilone D promotes axonal bud outburst and affects the cell cycle by inhibiting the transition of the G1 phase to the $S$ phase [26]. Together, these findings indicate that drugs or small molecules that stabilize microtubules may play an important role in nerve regeneration for SCI repair.

In this study, we found that Epothilone D promoted Apol8 expression and that Apol8 overexpression can facilitate the neuronal differentiation of NSCs. Furthermore, Apol8-overexpressing NSCs transplanted into the injured site after SCI preferred to differentiate into neurons rather than astrocytes. In addition, the newly generated neurons were involved in the regeneration of synaptic structures, which enhanced the recovery of motor function after SCI.

\section{Methods}

\section{Proliferation and differentiation of NSCs}

The NSCs were obtained from the spinal cords of postnatal mice (within $12 \mathrm{~h}$ of birth) and cultured in Dulbecco's modified Eagle's medium/F12 containing glucose (30\%), B27 supplement (2\%, 17504-044; Gibco), epidermal growth factor $(20 \mathrm{ng} / \mathrm{mL})$, fibroblast growth factor $(20 \mathrm{ng} / \mathrm{mL})$, and heparin $(1.83 \mu \mathrm{g} / \mathrm{mL})$ at $37^{\circ} \mathrm{C}$ in $5 \%$ 
$\mathrm{CO}_{2}$. After 10 days, the NSC spheres were digested to single cells and were attached to plates for differentiation in Dulbecco's modified Eagle's medium/F12 containing B27 supplement (2\%, 17504-044; Gibco), nonessential amino acids (1\%, 11140-050; Gibco), sodium pyruvate (1\%, 11360-070; Gibco), and penicillinstreptomycin (1\%, 15140-122; Gibco).

\section{Immunofluorescence and histological analysis}

Cells were fixed in $4 \%$ paraformaldehyde for $30 \mathrm{~min}$ and treated with $0.1 \%$ Triton $\mathrm{X}-100$ for $15 \mathrm{~min}$ at room temperature (RT). Cells were then blocked in $5 \%$ bovine serum albumin (BSA) for 30 min before primary antibody addition. Cells were incubated with primary antibodies for $12 \mathrm{~h}$ at $4^{\circ} \mathrm{C}$ (beta-tubulin III [TUJ1] antibody: ab18207, rabbit, 1:500; microtubule-associated protein 2 [MAP2] antibody: ab5392, chicken, 1:500; glial fibrillary acidic protein [GFAP] antibody: ab7260, rabbit, 1:500; all Abcam). After washing three times in Dulbecco's phosphate-buffered saline, Alexa Fluor-conjugated secondary antibodies were incubated at RT for $1 \mathrm{~h}$. The nuclei were stained by Hoechst 33342 (DH164-1, 1:1000, Sigma-Aldrich).

The spinal cords were obtained after paraformaldehyde fixation, dehydrated with sucrose $(20 \%$ and $30 \%$ sequentially), and then embedded in an optimal cutting temperature compound. The frozen tissue was sectioned at $12 \mu \mathrm{m}$, and the sections were incubated in 5\% BSA for $1 \mathrm{~h}$, and then with primary antibodies overnight at $4{ }^{\circ} \mathrm{C}$ (green fluorescence protein [GFP] antibody: ab13970, chicken, 1:500; doublecortin [DCX] antibody: ab18723, rabbit, 1:500; TUJ1 antibody: ab18207, rabbit, 1:500; neuronal N [NeuN] antibody: ab177487, rabbit, 1:500; GFAP antibody: ab7260, rabbit, 1:500; red fluorescent protein [RFP] antibody: ab8135, rabbit, 1:500; all Abcam; synaptophysin [SYN] antibody: MAB329, mouse, 1:500, Millipore; postsynaptic density protein 95 [PSD95] antibody: MAB1596, mouse, 1:500, Millipore; neurofilaments [NF] antibody: N4142, rabbit, 1:500, Sigma). On the second day, the sections were incubated with Alexa Fluorconjugated secondary antibodies (1:500, Invitrogen) at RT for $1 \mathrm{~h}$. The nuclei were stained with Hoechst 33342 dye $(1 \mathrm{mg} / \mathrm{mL})$.

\section{Western blotting}

Differentiated cells were scraped from the plate and were lysed in radioimmunoprecipitation assay buffer (WB-0071, China) for 20 min on ice. For each sample, $40 \mu \mathrm{g}$ of protein was then separated by sodium dodecyl sulfate polyacrylamide gel electrophoresis. The membranes were incubated with primary antibodies diluted to $1: 1000$ for $12 \mathrm{~h}$ at $4^{\circ} \mathrm{C}$ (glyceraldehyde 3-phosphate dehydrogenase [GAPDH] antibody: TA-08, mouse, Santa Cruz; TUJ1 antibody: ab18207, rabbit; MAP2 antibody: ab32454, rabbit; GFAP antibody: ab7260, rabbit; all Abcam). After three washes, the membranes were incubated with horseradish peroxidase-conjugated secondary antibodies at 1:3000 dilution for $1 \mathrm{~h}$ at RT.

\section{RNA sequencing (RNA-Seq)}

After SCI, mice were intraperitoneally injected with Epothilone D at $0.75 \mathrm{mg} / \mathrm{kg}$ for 5 days. Then, a 2-mm length of the spinal cord at the T8 injury site was obtained and sent to Shanghai Ouyi Biomedical Technology Co., Ltd. for RNA-Seq.

Quantitative real-time polymerase chain reaction (qRT-PCR) Total RNA of differentiated cells was extracted using TRIzol, and then the cDNA was obtained by reverse transcription using a reverse transcription kit (K1622; Thermo Fisher Scientific). qRT-PCR was performed using SYBR Green Master Mix (A25741, Thermo Fisher Scientific) to detect mRNA abundance. The primers used were as follows: Tuj1-F-5'-CATGGACAGTGTTCGGTCTG-3', R5'-CGCACGACATCTAGGACTGA-3'; Map2-F-5'-CT GGACATCAGCCTCACTCA-3', R-5'-AATAGGTGCC CTGTGACCTG-3'; Apols-F-5'-ATTGAGGAAGCCGC TGAGTA-3', R-5'-CAGGTTTGCTGTGAGTGCAT-3'; and Gapdh-F-5'-TTCCATCCTCCAGAAACCAG-3', R-5' -CCCTCGAACTAAGGGGAAAG-3'.

\section{Lentivirus production}

The coding sequence of Apols was inserted into the CD511B vector, which contains the GFP reporter gene, for lentivirus production in $293 \mathrm{~T}$ cells. The concentration (titer) of lentivirus was $10^{10} \mathrm{TU} / \mathrm{mL}$. The sequences of Apols primers were F-5' -CCGGAATTCATGGACCC TTCAGACT-3' (EcoRI site underlined), R-5'-CGAT TTAAATGAACACCTCCCCGTC-3' (SwaI site underlined). The lentivirus was used to infect NSCs during proliferation to enable Apols expression before neuronal differentiation of NSCs.

\section{Apol8-NSC-LOCS graft preparation}

The collagen nerve regeneration scaffold, LOCS, was soaked in poly-L-ornithine solution (P4957, Sigma) and then in fibronectin (F0895, Sigma) for $2 \mathrm{~h}$ at $37^{\circ} \mathrm{C}$. After three washes, LOCS were cut to 2-mm lengths and placed in bundles of four to create a LOCS beam graft. Then Apol8-overexpression NSCs were digested to single cells and a million cells were attached to each LOCS beam. After incubation for $24 \mathrm{~h}$, the graft was transplanted into the SCI injury site.

\section{Animal surgery and functional evaluation}

Eight-week-old C57BL/6N mice were anesthetized by intraperitoneal injection of sodium pentobarbital (1\%; 50 $\mathrm{mg} / \mathrm{kg}$ ), and then, a 1-mm section of the spinal cord was 
removed at the level of $\mathrm{T} 8$. When the fluid had ceased to ooze from the damaged area, the prepared graft was carefully placed in the damaged area. Finally, the muscle and skin were sutured. Penicillin was injected intraperitoneally for 1 week, and bladder massage was performed twice a day to assist urination. Motor function was evaluated weekly according to the Basso Mouse Scale (BMS) in a double-blind format [27]. Eight weeks after the surgery, the mice were anesthetized with $1 \%$ sodium pentobarbital, and the electrophysiological analyses were performed.

\section{Retrograde tracing using a pseudotyped rabies virus}

A retrovirus was used to label proliferating NSCs [28], including normal NSCs and those treated with Epothilone D in vitro. The labeled NSCs were transplanted into the injured site. Seven weeks after SCI, a pseudotyped rabies virus (Rabies-EnvA-mCh) was injected into an undamaged site about $1 \mathrm{~mm}$ from the caudal end of the damaged area $[29,30]$. Another week later, the mice were euthanized, and the spinal cord was obtained for histological analysis [17].

\section{Results}

\section{Epothilone D promotes the neuronal differentiation of} NSCs

Epothilone D can stabilize microtubules [31] and can promote functional improvement of hind limb function in contusion spinal cord rats [32]. Some drugs that stabilize microtubules are used for SCI repair because they can promote NSC differentiation into neurons [20]; however, whether Epothilone D has this effect is unclear. We therefore explored the effect of Epothilone D on NSC differentiation. Under differentiation conditions, Epothilone D was added. On the 6th day, as shown in Fig. 1a, Epothilone D promoted NSC differentiation into neurons rather than astrocytes. The percentage of cells differentiating into neurons was promoted from $4.92 \pm$ $0.73 \%$ in the control group to $16.68 \pm 1.11 \%$ in the Epothilone D group, while the percentage of cells differentiating into astrocytes decreased from $29.33 \pm 6.40 \%$ in the control group to $10.13 \pm 0.83 \%$ in the Epothilone $\mathrm{D}$ group (Fig. $1 \mathrm{a}-\mathrm{c}$ ). The mRNA and protein levels of the neuronal markers TUJ1 and MAP2 were also detected on the 6th and 12th day of differentiation, respectively. The results showed that Epothilone D promoted mRNA expression of both TUJ1 and MAP2 (Fig. 1d, e). Western blot results were consistent with the expression levels of mRNAs (Fig. 1f, g). Together, these results demonstrated that Epothilone D promoted the differentiation of NSCs into neurons rather than astrocytes by inhibiting the proliferation of NSCs.

\section{Epothilone D can facilitate the reconstruction of neural circuits}

Having shown that Epothilone D can promote the neuronal differentiation of NSCs in vitro, we then explored whether NSCs differentiated by Epothilone D

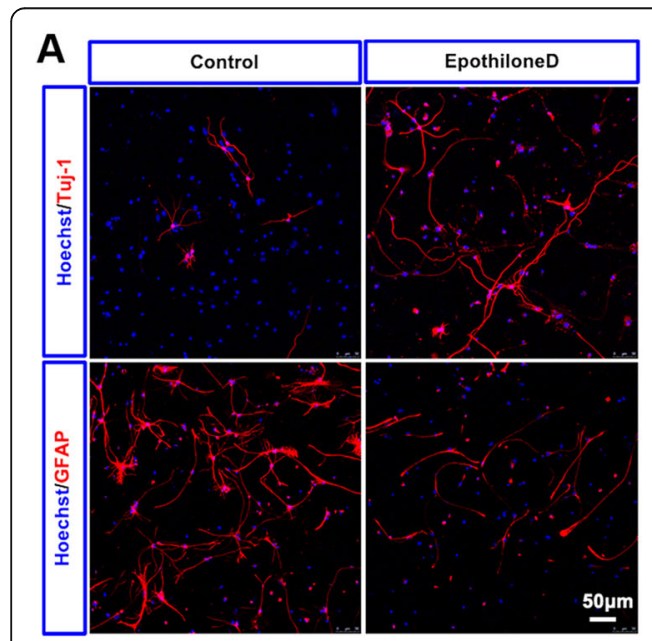

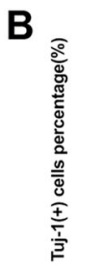
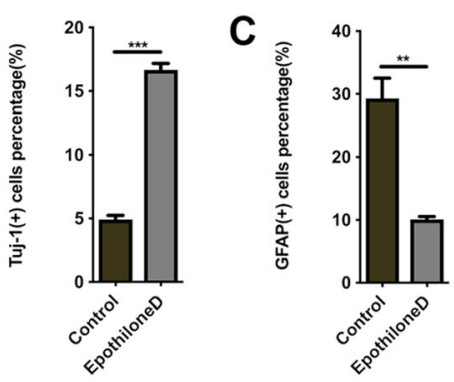

$\mathbf{F}$

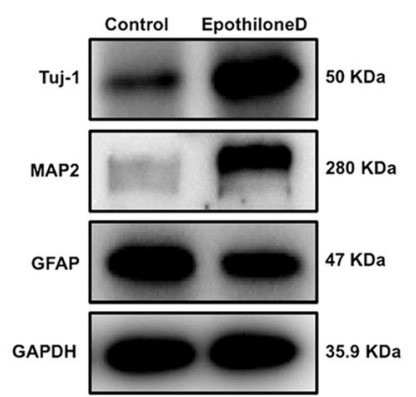

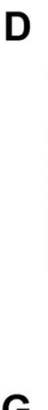
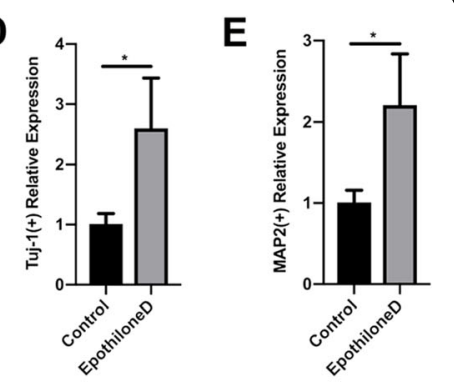

G

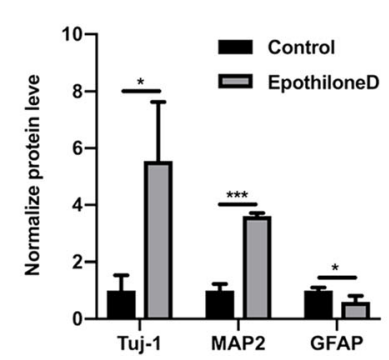

Fig. 1 Epothilone D promotes NSC differentiation into neurons. a Epothilone D promoted the neuronal differentiation of spinal cord NSCs and inhibited their differentiation into astrocytes. Scale bars, $50 \mu \mathrm{m}$. b Quantification of percentages of TUJ1(+) cells among differentiated cells cultured with or without Epothilone D. c Quantification of percentages of GFAP(+) cells among differentiated cells cultured with or without Epothilone D. d, e Tuj1 and NeuN mRNA levels in lysates of differentiated cells were analyzed by qRT-PCR after Epothilone D induction. $\mathbf{f}, \mathbf{g}$ Western blot detection of the effect of Epothilone D on neuronal differentiation of NSCs. Error bars represent the mean \pm SD 
could promote the reconstruction of neural circuits in the injured site after SCI. NSCs were stimulated with Epothilone D and were then labeled by infection with a retrovirus. Seven weeks after transplantation, pseudotyped rabies virus (Rabies-EnvA-mCh) was injected to trace the connectivity of newborn neurons in the spinal cord (mCh-positive cells represent traced cells and $\mathrm{GFP} / \mathrm{mCh}$ double-positive cells represent newborn neurons). One week after virus injection, the ratio of new connectivity at the T8 injured site in the
Epothilone D-NSC group was higher than that in the NSC group (Fig. 2a, c). However, the signal transmission was only detected in the Epothilone D-NSC group in the cervical region away from the damaged area (Fig. 2a, b). Immunofluorescence staining of NeuN showed that the signals transmitted by retrograde tracing technology were received by mature neurons in normal tissues; that is, functionally mature neurons in normal tissues were involved in the reconstruction of neural circuits with new mature neurons

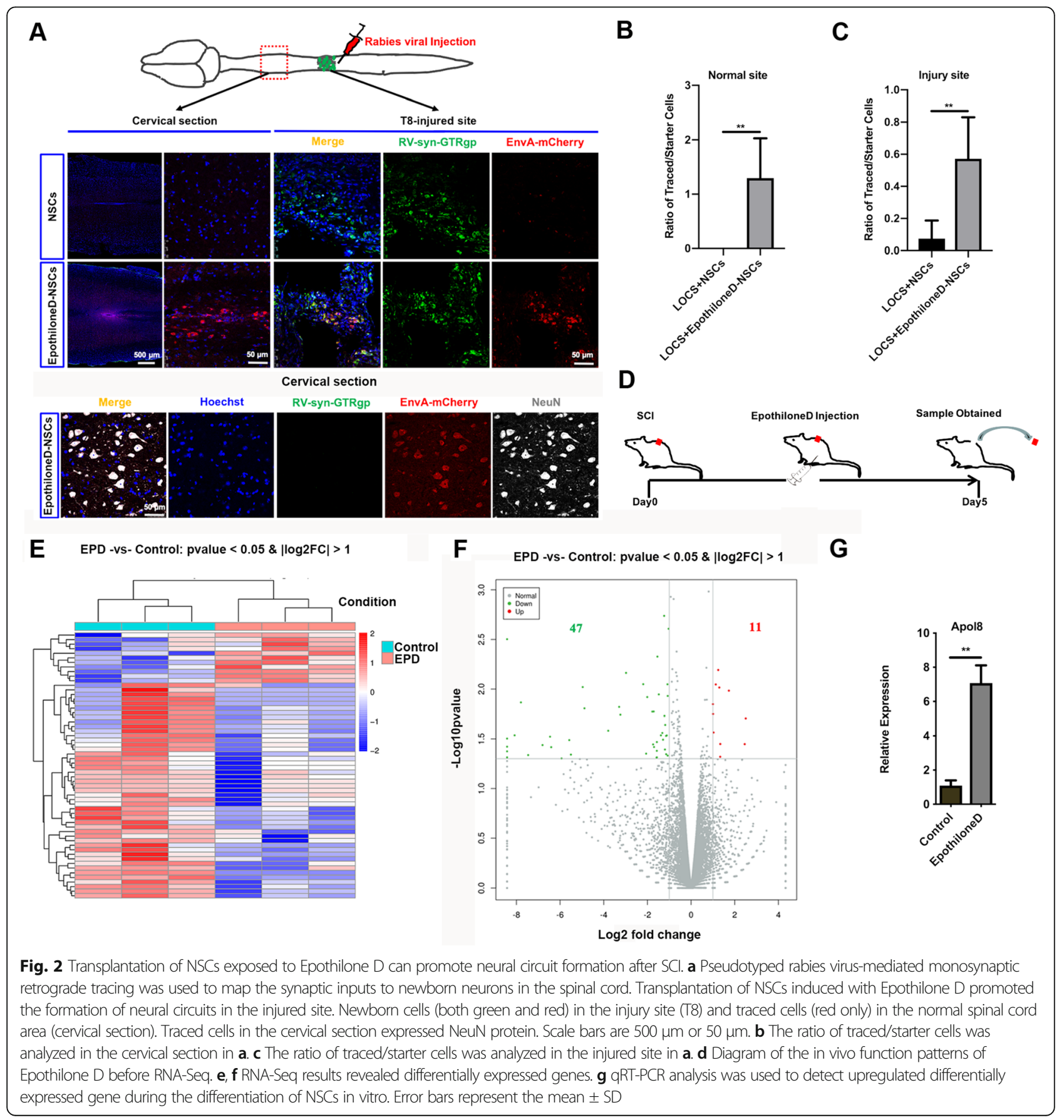


in damaged areas in the Epothilone D-NSC group (Fig. 2a).

To explore the mechanism by which Epothilone D promotes neuronal differentiation of NSCs, RNA-Seq was performed to determine differentially expressed genes in the control and Epothilone D addition groups. After SCI, Epothilone D was administered at the injured site, followed by daily intraperitoneal injections of Epothilone D for 5 days. Then, a 2-mm-long section of spinal cord tissue around the injury area was taken for RNA-Seq (Fig. 2d). Differentially expressed genes are displayed in the form of a heat map (Fig. 2e). Fortyseven genes were downregulated, and only 11 genes were upregulated (Fig. 2f). We speculate that some upregulated genes may be involved in the neuronal differentiation of NSCs by Epothilone D. qRT-PCR showed that Apol8 was upregulated by Epothilone $\mathrm{D}$ during neuronal differentiation of NSCs in vitro (Fig. 2g). Therefore, we infer that Epothilone D may promote the neuronal differentiation that is involved in the reconstruction of neural circuits through Apol8.

\section{Epothilone D promotes neuronal differentiation of NSCs through Apol8}

Next, we tested whether the upregulated differentially expressed genes were involved in the neuronal differentiation process of NSCs regulated by Epothilone D. Differentially expressed genes were inserted into the lentivirus overexpression vectors to explore their function, and overexpression of Apols in NSCs was observed to promote neuronal differentiation of NSCs. The rate of neuronal differentiation was below $10 \%$ after 6 days of differentiation under spontaneous differentiation conditions. However, the neuronal differentiation rate was increased to $21.83 \pm 2.68 \%$ by lentiviral overexpression of Apols in NSCs. Conversely, the neuronal differentiation rate decreased to $4.40 \pm 2.25 \%$ under Apol8-RNAi conditions (Fig. 3a, b). With a longer differentiation time (12 days), the percentage of MAP2(+) cells increased from 8.94 \pm $1.45 \%$ in the control group to $23.72 \pm 3.16 \%$ in the Apol8 overexpression group and decreased to $3.13 \pm$ $1.45 \%$ in the Apol8-RNAi group (Fig. 3a, c). The effect of Apols on neuronal differentiation of NSCs was also shown to be evaluated by western blotting. Consistent with the immunofluorescence results, TUJ1 and MAP2 expression were improved by Apols overexpression and inhibited by Apol8-RNAi during neuronal differentiation of NSCs (Fig. 3d, e). We therefore concluded that Apols was involved in the neuronal differentiation of NSCs.

Next, we further explored whether Epothilone D can promote neuronal differentiation of NSCs through Apols overexpression. We demonstrated that Epothilone D and
Apol8 can both promote neuronal differentiation; therefore, we designed an experiment in which Apols was first knocked down by Apol8-RNAi technology, and then Epothilone D was used for induction. Epothilone D increased the percentage of TUJ1(+) neurons from $4.32 \pm$ $1.64 \%$ in the control group to $14.32 \pm 3.55 \%$, and the percentage of mature neurons from $2.56 \pm 0.74$ to 12.81 $\pm 0.64 \%$ (Fig. $3 \mathrm{f}-\mathrm{h}$ ), while the percentage of astrocytes was decreased. Surprisingly, Epothilone D did not have a positive effect on neuronal differentiation following Apol8 knockdown by Apol8-RNAi. As a result, the NSCs preferred to differentiate into astrocytes (Fig. 3f, i). In summary, Apols was involved in the neuronal differentiation of NSCs induced by Epothilone D.

\section{NSCs overexpressing Apol8 are more likely to differentiate into neurons after transplantation}

After demonstrating that Epothilone D can promote the neuronal differentiation of NSCs by upregulating Apol8, we wondered whether the transplantation of NSCs overexpressing Apols can overcome the inhibitory microenvironment by enhancing their intrinsic neuronal differentiation ability after SCI. First, lentivirus-mediated Apol8 overexpression was used to replace Epothilone Dinduced downstream Apols expression, to endow NSCs with the potential to differentiate into neurons (Fig. 4a, b). Then, the NSCs were loaded onto LOCS and transplanted into the injured site after SCI (Fig. 4c, d). Two weeks later, NSCs tended to have differentiated into astrocytes rather than immature neurons (Fig. 4e). The percentage of $\mathrm{GFP}(+) \mathrm{DCX}(+)$ transplanted NSCs was $15.89 \pm 3.99 \%$, and the percentage of $\mathrm{GFP}(+) \operatorname{GFAP}(+)$ cells was as high as $47.75 \pm 7.09 \%$ (Fig. 4f, g). However, the Apol8-NSCs loaded onto LOCS overcame the inhibitory SCI microenvironment and preferentially differentiated into neurons (46.68 $\pm 14.76 \%)$ rather than astrocytes $(14.37 \pm 5.16 \%)$ at the injury site (Fig. $4 \mathrm{e}-\mathrm{g}$ ). The proportion of early neurons was increased from about 15 to $46.68 \% \pm 14.76 \%$ while the proportion of astrocytes was decreased from about 47 to $14.37 \pm 5.16 \%$ (Fig. 4e-g). Next, the differentiation of NSCs was examined at 8 weeks after SCI. More Apol8-NSCs differentiated into neurons compared with non-transformed NSCs in the injured site (Fig. 4h). The percentage of TUJ1(+) cells was only $14.33 \pm 3.00 \%$ in the NSC transplantation group but more than three times this in the Apol8-NSC group (Fig. 4i). At the same time, the proportion of astrocytes was still lower in the Apol8-NSC group $(17.64 \pm 4.20 \%)$ compared with that in the nontransformed NSC group (48.52 $\pm 6.89 \%)$ (Fig. 4k). Interestingly, Apols also promoted the differentiation of mature neurons. Our results demonstrated that $12.08 \%$ of Apol8-NSCs differentiated into $\mathrm{NeuN}(+)$ neurons while no mature neurons were detected in the NSC 


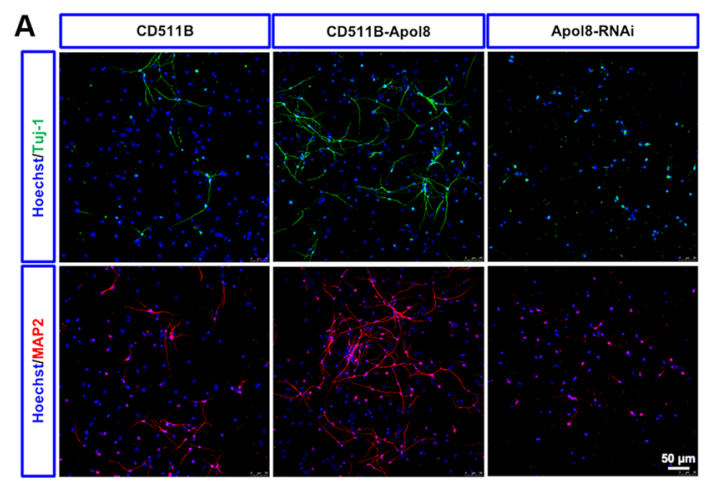

B

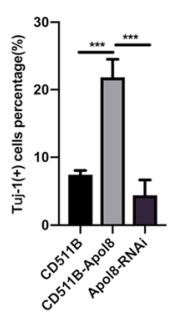

C

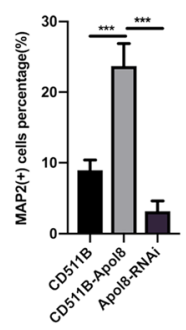

D

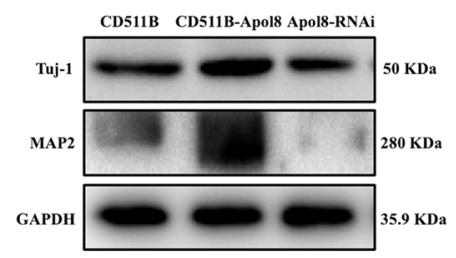

E

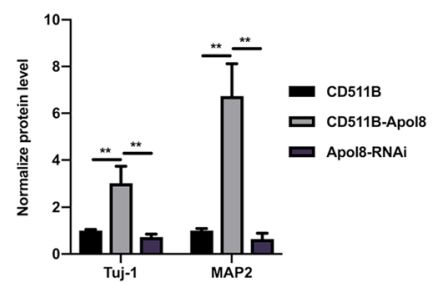

$\mathbf{F}$

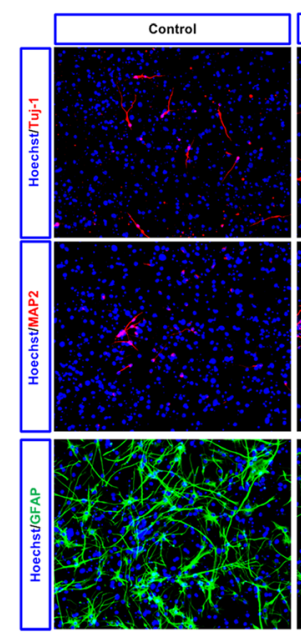

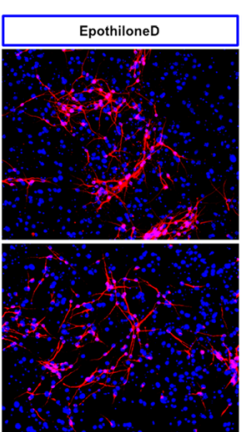
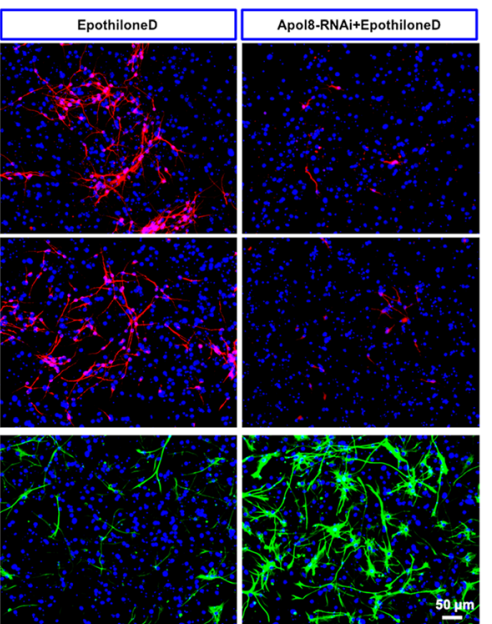

G

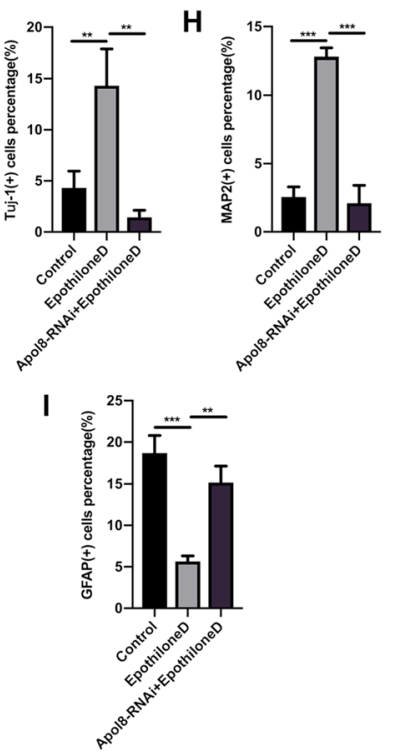

Fig. 3 Epothilone D promotes neuronal differentiation of NSCs by upregulating Apol8. a Effects of Apol8 on neuronal differentiation of NSCS through TUJ1 or MAP2 assessed by immunofluorescence staining. b, c Quantification of percentages of TUJ1(+) and MAP2(+) cells among differentiated cells cultured under Apo/8 overexpression or Apol8-RNAi conditions. d, e Western blotting was used to detect the effect of Apo/8 overexpression or Apol8-RNAi on neuronal differentiation of NSCs. $\mathbf{f}$ Effects of Epothilone D on neuronal differentiation of NSCs with or without the intervention of Apo/8-RNAi, assessed by immunofluorescence staining. $\mathbf{g - i}$ Quantification of percentages of neurons or astrocytes in $\mathbf{F}$. Error bars represent the mean \pm SD. All scale bars, $50 \mu \mathrm{m}$

transplantation group (Fig. 4j). We also detected synapse structures in the Apols-NSC group through immunofluorescence staining for SYN and PSD95. The transplanted NSCs $(\mathrm{GFP}+)$ were surrounded by synaptic structures $(\mathrm{NF}+\mathrm{SYN}+$ or NF+PSD95+) (Fig. 4l). All of these results demonstrated that Apols can help to improve the intrinsic neuronal differentiation ability of NSCs and promote the differentiation of transplanted
NSCs into mature neurons by overcoming the inhibitory microenvironment after SCI, which contributes to the reconstruction of synaptic structures. This indicates that either Epothilone D-induced Apol8 expression in vitro or lentivirus-mediated Apols overexpression in vivo in NSCs can also promote neuronal differentiation and suggests that Apol8 may play a similar role to Epothilone $\mathrm{D}$, as a downstream molecule. 


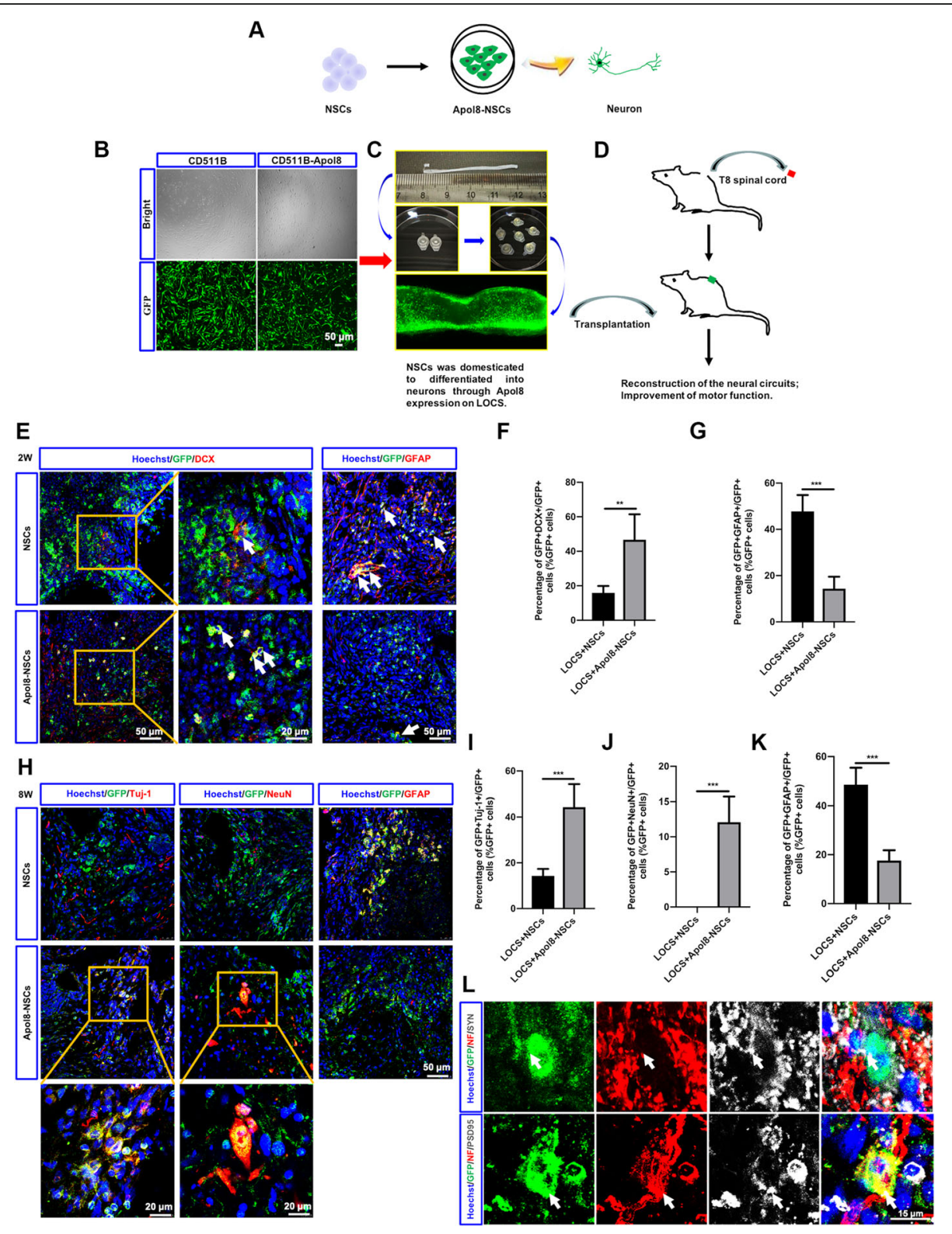

Fig. 4 Apol8 promotes neuronal differentiation of transplanted NSCs in vivo. a Patterns of neuronal differentiation of Apol8-NSCs. b Apol8 overexpression in NSCs mediated by lentivirus. Scale bars, 50 mm. c NSCs with or without Apol8 were loaded onto LOCS. d LOCS grafts loaded with NSCs were transplanted in the injury site after SCI. e Two weeks after transplantation, the spinal cord was dissected, and DCX and GFAP expression was determined by immunofluorescence staining. Scale bars are $50 \mu \mathrm{m}$ or $20 \mu \mathrm{m}$. $\mathbf{f}$ Percentage of GFP(+)DCX(+)/GFP(+) cells in e. $\mathbf{g}$ Percentage of GFP(+)GFAP(+)/GFP(+) cells in $\mathbf{e}$. $\mathbf{h}$ Eight weeks after transplantation, the spinal cord was dissected, and TUJ1, NeuN, and GFAP expression was determined by immunofluorescence staining. Scale bars are $50 \mu \mathrm{m}$ or $20 \mu \mathrm{m}$. i Percentage of GFP(+)Tuj-1(+)/GFP(+) cells in $\mathbf{h}$. $\mathbf{j}$ Percentage of GFP(+)NeuN(+)/GFP(+) cells in $\mathbf{h}$. $\mathbf{k}$ Percentage of GFP(+)GFAP(+)/GFP(+) cells in $\mathbf{h}$. I Transplantation of Apo/8-NSCs on LOCS promotes the formation of synaptic structures in the injured site. Scale bars, $15 \mu \mathrm{m}$. Error bars represent the mean \pm SD

Apol8-NSC transplantation enhances the recovery of motor function in mice with complete transection $\mathrm{SCI}$

Epothilone D can help in functional recovery [32], and we have demonstrated that Epothilone D can facilitate the reconstruction of neural circuits through Apol8. We next tested whether the direct overexpression of Epothilone D-upregulated Apols in NSCs can promote functional recovery in animals with SCI. The BMS was used to assess motor function after treatment for 8 weeks. The untreated mice showed slight ankle movements in their hind limbs (mean BMS score $1.2 \pm 0.45)$. Both NSC and Apol8-NSC transplantation promoted functional recovery. However, mice occasionally stood on the balls of their feet in 
the Apol8-NSC transplantation group (mean BMS score $3.2 \pm 0.45$ ) while mice only achieved extensive ankle movement in the NSC transplantation group (mean BMS score $2.2 \pm 0.45$ ) (Fig. 5a, b). Electrophysiological results also showed that Apol8-NSC transplantation contributed to better electrophysiological recovery compared with NSC transplantation. Apol8-NSC-transplanted mice displayed a shorter latent period $(3.48 \pm 1.83 \mathrm{~ms})$ and stronger amplitude $(0.08 \pm 0.04 \mathrm{mV})$ compared with mice in the NSC transplantation group (mean latent period $8.77 \pm 3.55$ ms; mean amplitude $0.02 \pm 0.01 \mathrm{mV}$ ) (Fig. $5 \mathrm{c}-\mathrm{e}$ ). Our functional experiments showed that Apol8-NSC transplantation improved functional recovery after SCI, including motor function and electrophysiological function.

\section{Discussion}

The inhibitory microenvironment of an injured site prevents transplanted NSCs from differentiating into mature neurons, which usually results in failed functional connections [33]. Previous studies have reported that Epothilone D can promote axon regrowth and facilitate functional recovery after SCI [34]. However, it remains unclear whether Epothilone D can contribute to SCI repair by promoting the neuronal differentiation of NSCs. In this study, we first found that Epothilone D can contribute to the neuronal differentiation of NSCs in vitro. Epothilone D can stabilize cell microtubules, which results in axon extension [35]. Furthermore, Epothilone D can inhibit cell proliferation through the regulation of cell cycle G1 checkpoint proteins [26]. The generation of neurons can be regulated by the cell cycle, and the

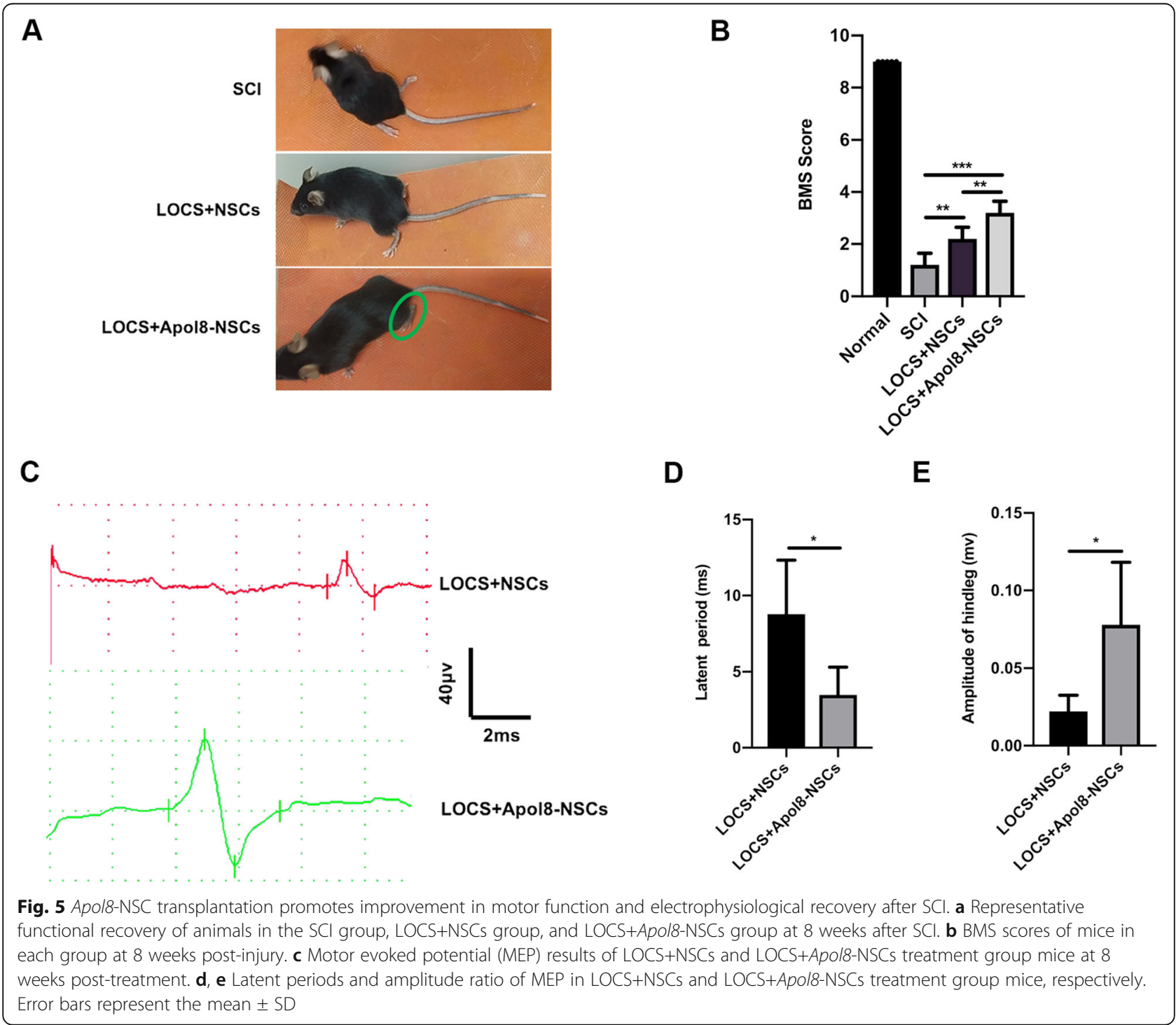


distribution of genetic material determines the fate of cells through spindle microtubule stretching, which may be affected by some drugs that stabilize microtubules [16]. These findings indicate that the regulation of microtubules involved in the cell cycle can be affected by drugs such as Epothilone D, which may be a significant factor in the neuronal differentiation of NSCs; this is consistent with our present study. Our study points to a new strategy for screening neurogenic drugs and therapeutic drugs for SCI.

NSC transplantation has recently been used in SCI treatment [36]. However, directional differentiation is still a problem for SCI repair. The inhibitory microenvironment allows more NSCs to differentiate into astrocytes rather than neurons [6]. Gene-modified NSC therapies, in which fate determination of NSCs is regulated, are promising for SCI repair. Zeng et al. showed that NT3-overexpressing NSCs can promote TRKCoverexpressing NSCs to differentiate into neurons [37, 38]. Here, we demonstrated that Epothilone D can facilitate neuronal circuit construction in vivo and can promote the neuronal differentiation of NSCs through the downstream target, Apol8. We also demonstrated that overexpression of Apol8 in NSCs can improve the percentage of neurons. To the best of our knowledge, this is the first time that Apols has been shown to be involved in the neuronal differentiation of NSCs. Our previous study also showed that NSC transplantation with directional neuronal differentiation can promote functional recovery after SCI [39]. Therefore, in the present study, we attempted in vitro directional neuronal differentiation of NSCs by means of gene modification and then used these cells for SCI repair. Our results demonstrated improved neuronal differentiation of transplanted Apol8-NSCs compared with NSCs. The in vitro differentiation experiment also showed that the percentage of neuronal differentiation was higher in the Apol8-overexpression group compared with that in the Epothilone D group, which indicated that specific downstream target intervention plays a more important role in the fate determination of NSCs, which is significant for the treatment of SCI.

Understanding of the microenvironment after SCI is still very limited, and combination therapy has great potential for SCI repair. Biomaterials are widely used to improve repair after SCI [40]. Injectable and resorbable polypeptide hydrogels can enable axons to regrow across the SCI lesion site through the prolonged release of growth factors [41, 42]. We have previously reported that the collagen nerve regeneration scaffold, LOCS, has good biocompatibility and degradation properties and can guide the orderly growth of cells [43]. This indicated that LOCS can be used as an effective vector for delivering exogenous cells for cell transplantation therapy. We also demonstrated that transplantation of human mesenchymal stem cells and exogenous NSCs combined with LOCS can inhibit scar tissue formation, which can block nerve regrowth $[44,45]$. Here, exploiting the good tissue compatibility of LOCS and genetic engineering technology, we overexpressed a target gene in NSCs after exploring the mechanism of Epothilone D function. Then, we delivered gene-modified NSCs combined with LOCS to the injury site. On the one hand, the SCI microenvironment was improved by LOCS, which guarantees the survival of the transplanted cells. On the other hand, the directional neuronal differentiation of NSCs involving genetic engineering makes directional neurogenesis possible and provides sources of cells for the reconstruction of neural circuits after SCI. Our results demonstrated that combination therapy promotes motor function recovery after complete SCI by combining LOCS and directed neuronal differentiation.

\section{Conclusions}

This study demonstrated that Epothilone D promotes neuronal differentiation of NSCs by upregulating Apols. The transplantation of NSCs overexpressing Apols promoted the differentiation of NSCs into neurons and inhibited their differentiation into astrocytes in the injury site after SCI. Furthermore, differentiated neurons contributed to the reconstruction of neural circuits and the improvement of motor function after SCI, which is of significance for SCI repair.

\section{Abbreviations}

BMS: Basso Mouse Scale; BSA: Bovine serum albumin; CNS: Central nervous system; DCX: Doublecortin; GAPDH: Glyceraldehyde 3-phosphate dehydrogenase; GFAP: Glial fibrillary acidic protein; GFP: Green fluorescence protein; LOCS: Linear ordered collagen scaffold; MAP 2: Microtubule-associated protein 2; NeuN: Neuronal N; NF: Neurofilaments; NSCs: Neural stem cells; PSD95: Postsynaptic density protein 95; qRT-PCR: Quantitative real-time polymerase chain reaction; RFP: Red fluorescent protein; RNA-Seq: RNA sequencing; RT: Room temperature; SCl: Spinal cord injury;

SYN: Synaptophysin; TUJ1: Beta-tubulin III

\section{Acknowledgements}

We thank Dr. Weixiang Guo at the Institute of Genetics and Developmental Biology in Beijing for the guidelines for the rabies virus-based retrograde tracing technique. We also thank Jeremy Allen, PhD, and Bronwen Gardner, PhD, from Liwen Bianji, Edanz Editing China (www.liwenbianji.cn/ac), for editing the English text of a draft of this manuscript.

\section{Authors' contributions}

W.W.X. made substantial contributions to the conception and design, acquisition of the data, analysis and interpretation of the data, and manuscript writing. H.P.Z. contributed to the animal operations and data analysis. Y.H.F. provided functional evaluations for the animal experiments. Z.F.X. contributed to the structure of the manuscript. Y.N.Z. provided the LOCS and contributed to the interpretation of the data. W.Y.L. contributed to draw materials. B.X. and Y.Y.Y. contributed to the animal urinary care. B.C. contributed to the language modification. J.Y.L. contributed to the ordering of reagents. Y.C. provided guidance in the experimental techniques. Y.S. contributed to the formal analysis. J.W.D. made substantial contributions to the conception and design, financial support, and analysis and interpretation of the data. All authors read and approved the final version to be published. 


\section{Funding}

This work was supported by grants from the National Natural Science Foundation of China (81891000), the Strategic Priority Research Program of the Chinese Academy of Sciences (XDA16040700), and the National Key R\&D Program of China (2017YFA0104701, 2017YFA0104704, and 2016YFC1101501). We also received support from the National Natural Science Foundation of China (32071338, 82071403, U1738109, and 31970640)

\section{Availability of data and materials}

The data are available from the corresponding author on reasonable request.

\section{Declarations}

\section{Ethics approval and consent to participate}

All institutional and national guidelines for the care and use of laboratory animals were followed, and the ethics approval was obtained from the Laboratory Animal Ethics Committee, Institute of Genetics and Developmental Biology, Chinese Academy of Sciences. No human subjects were involved in this study.

\section{Consent for publication}

Not applicable.

\section{Competing interests}

The authors declare that they have no competing interests.

\section{Author details}

${ }^{1}$ State Key Laboratory of Molecular Developmental Biology, Institute of Genetics and Developmental Biology, Chinese Academy of Sciences, Beijing 100101, China. ${ }^{2}$ University of the Chinese Academy of Sciences, Beijing 100190, China. ${ }^{3}$ Reproductive and Genetic Center of National Research Institute for Family Planning, Beijing 100081, China. ${ }^{4}$ Key Laboratory for Nano-Bio Interface Research, Division of Nanobiomedicine, Suzhou Institute of Nano-Tech and Nano-Bionics, Chinese Academy of Sciences, Suzhou 215123, China.

Received: 4 January 2021 Accepted: 9 May 2021

Published online: 26 May 2021

\section{References}

1. Hagg T, Oudega M. Degenerative and spontaneous regenerative processes after spinal cord injury. J Neurotrauma. 2006;23(3-4):264-80. https://doi.org/1 0.1089/neu.2006.23.263.

2. Ahuja CS, Nori S, Tetreault L, Wilson J, Kwon B, Harrop J, et al. Traumatic spinal cord injury-repair and regeneration. Neurosurgery. 2017;80(3S):S9-S22. https://doi.org/10.1093/neuros/nyw080.

3. Akbik F, Cafferty WBJ, Strittmatter SM. Myelin associated inhibitors: a link between injury-induced and experience-dependent plasticity [in English]. Exp Neurol. 2012;235(1):43-52. https://doi.org/10.1016/j.expneurol.2011.06.006.

4. Shi R, Pryor JD. Pathological changes of isolated spinal cord axons in response to mechanical stretch. Neuroscience. 2002;110(4):765-77. https:// doi.org/10.1016/S0306-4522(01)00596-6.

5. Assinck P, Duncan GJ, Hilton BJ, Plemel JR, Tetzlaff W. Cell transplantation therapy for spinal cord injury [in English]. Nat Neurosci. 2017;20(5):637-47. https://doi.org/10.1038/nn.4541.

6. Mothe AJ, Tator $\mathrm{CH}$. Review of transplantation of neural stem/progenitor cells for spinal cord injury. Int J Dev Neurosci. 2013;31(7):701-13. https://doi. org/10.1016/j.ijdevneu.2013.07.004.

7. Lu P, Kadoya K, Tuszynski MH. Axonal growth and connectivity from neura stem cell grafts in models of spinal cord injury. Curr Opin Neurobiol. 2014; 27:103-9. https://doi.org/10.1016/j.conb.2014.03.010.

8. Neirinckx V, Cantinieaux D, Coste C, Rogister B, Franzen R, Wislet-Gendebien S. Concise review: spinal cord injuries: how could adult mesenchymal and neural crest stem cells take up the challenge? [in English]. Stem Cells. 2014; 32(4):829-43. https://doi.org/10.1002/stem.1579.

9. Cummings BJ, Uchida N, Tamaki SJ, Salazar DL, Hooshmand M, Summers R, et al. Human neural stem cells differentiate and promote locomotor recovery in spinal cord-injured mice. Proc Natl Acad Sci U S A. 2005:102(39): 14069-74. https://doi.org/10.1073/pnas.0507063102.
10. Hofstetter CP, Holmstrom NAV, Lilja JA, et al. Allodynia limits the usefulness of intraspinal neural stem cell grafts; directed differentiation improves outcome [in English]. Nat Neurosci. 2005;8(3):346-53. https://doi.org/10.103 8/nn1405.

11. Lu P, Wang Y, Graham L, McHale K, Gao M, Wu D, et al. Long-distance growth and connectivity of neural stem cells after severe spinal cord injury. Cell. 2012;150(6):1264-73. https://doi.org/10.1016/j.cell.2012.08.020.

12. Martino G, Pluchino S. The therapeutic potential of neural stem cells [in English]. Nat Rev Neurosci. 2006;7(5):395-406. https://doi.org/10.1038/nrn1908.

13. Setoguchi T, Nakashima K, Takizawa T, Yanagisawa M, Ochiai W, Okabe M, et al. Treatment of spinal cord injury by transplantation of fetal neural precursor cells engineered to express BMP inhibitor. Exp Neurol. 2004 189(1):33-44. https://doi.org/10.1016/j.expneurol.2003.12.007.

14. Wang B, Xiao ZF, Chen B et al. Nogo-66 promotes the differentiation of neural progenitors into astroglial lineage cells through mTOR- STAT3 pathway. PLoS One. 2008;3(3):e1856. https://journals.plos.org/plosone/a rticle?id=10.1371/journal.pone.0001856.

15. Das RK, Zouani OF. A review of the effects of the cell environment physicochemical nanoarchitecture on stem cell commitment [in English]. Biomaterials. 2014;35(20):5278-93. https://doi.org/10.1016/j.biomaterials.2014.03.044.

16. Geng A, Qiu RX, Murai K, Liu J, Wu X, Zhang H, et al. KIF20A/MKLP2 regulates the division modes of neural progenitor cells during cortical development [in English]. Nat Commun. 2018;9(1):2707. https://doi.org/10.1 038/s41467-018-05152-1

17. Xue W, Zhao Y, Xiao Z, Wu X, Ma D, Han J, et al. Epidermal growth factor receptor-extracellular-regulated kinase blockade upregulates TRIM32 signaling cascade and promotes neurogenesis after spinal cord injury. Stem Cells. 2020:38(1):118-33, https://doi.org/10.1002/stem.3097.

18. Yin W, Li X, Zhao YN, Tan J, Wu S, Cao Y, et al. Taxol-modified collagen scaffold implantation promotes functional recovery after long-distance spinal cord complete transection in canines [in English]. Biomater Sci-Uk. 2018;6(5):1099-108. https://doi.org/10.1039/C8BM00125A.

19. Fan CX, Li X, Zhao YN, Xiao Z, Xue W, Sun J, et al. Cetuximab and Taxol comodified collagen scaffolds show combination effects for the repair of acute spinal cord injury [in English]. Biomater Sci-Uk. 2018;6(7):1723-34. https://doi.org/10.1039/C8BM00363G

20. Li XR, Fan CX, Xiao ZF, Zhao Y, Zhang H, Sun J, et al. A collagen microchannel scaffold carrying paclitaxel-liposomes induces neuronal differentiation of neural stem cells through Wnt/beta-catenin signaling for spinal cord injury repair [in English]. Biomaterials. 2018;183:114-27. https:// doi.org/10.1016/j.biomaterials.2018.08.037.

21. Crunkhorn S. CNS injury. Microtubule stabilizer repairs spinal cord injury [in English]. Nat Rev Drug Discov. 2015;14(5):310. https://doi.org/10.1038/nrd4616.

22. Ruschel J, Hellal F, Flynn KC, Dupraz S, Elliott DA, Tedeschi A, et al. Systemic administration of Epothilone $B$ promotes axon regeneration after spinal cord injury [in English]. Science. 2015;348(6232):347-52. https://doi.org/1 $0.1126 /$ science.aaa2958.

23. Zhang B, Carroll J, Trojanowski JQ, Yao Y, Iba M, Potuzak JS, et al. The microtubule-stabilizing agent, Epothilone $\mathrm{D}$, reduces axonal dysfunction, neurotoxicity, cognitive deficits, and Alzheimer-like pathology in an interventional study with aged tau transgenic mice [in English]. J Neurosci. 2012;32(11):3601-11. https://doi.org/10.1523/JNEUROSCI.4922-11.2012.

24. La Regina G, Coluccia A, Naccarato V, et al. Towards modern anticancer agents that interact with tubulin [in English]. Eur J Pharm Sci. 2019;131:5868. https://doi.org/10.1016/j.ejps.2019.01.028.

25. Brunden KR, Zhang B, Carroll J, Yao Y, Potuzak JS, Hogan AML, et al. Epothilone D improves microtubule density, axonal integrity, and cognition in a transgenic mouse model of tauopathy [in English]. J Neurosci. 2010; 30(41):13861-6. https://doi.org/10.1523/JNEUROSCI.3059-10.2010.

26. Kim TJ, Lim Y, Kim DW, Kwon JS, Son JH, Jin YR, et al. Epothilone D, a microtubule-stabilizing compound, inhibits neointimal hyperplasia after rat carotid artery injury by cell cycle arrest via regulation of G1-checkpoint proteins [in English]. Vasc Pharmacol. 2007;47(4):229-37. https://doi.org/10.1 016/j.vph.2007.06.009.

27. Basso DM, Fisher LC, Anderson AJ, Jakeman LB, Mctigue DM, Popovich PG Basso Mouse Scale for locomotion detects differences in recovery after spinal cord injury in five common mouse strains. J Neurotrauma. 2006;23(5): 635-59. https://doi.org/10.1089/neu.2006.23.635.

28. Smrt RD, Szulwach KE, Pfeiffer RL, Li X, Guo W, Pathania M, et al. MicroRNA miR-137 regulates neuronal maturation by targeting ubiquitin ligase mind bomb-1. Stem Cells. 2010;28(6):1060-70. https://doi.org/10.1002/stem.431. 
29. Vivar C, Potter MC, Choi J, Lee JY, Stringer TP, Callaway EM, et al. Monosynaptic inputs to new neurons in the dentate gyrus. Nat Commun. 2012;3(1):1107. https://doi.org/10.1038/ncomms2101.

30. Wickersham IR, Lyon DC, Barnard RJ, et al. Monosynaptic restriction of transsynaptic tracing from single, genetically targeted neurons. Neuron. 2007;53(5):639-47. https://doi.org/10.1016/j.neuron.2007.01.033.

31. Penazzi L, Tackenberg C, Ghori A, Golovyashkina N, Niewidok B, Selle K, et al. $A \beta$-mediated spine changes in the hippocampus are microtubuledependent and can be reversed by a subnanomolar concentration of the microtubule-stabilizing agent Epothilone D. Neuropharmacology. 2016;105: 84-95. https://doi.org/10.1016/j.neuropharm.2016.01.002.

32. Ruschel J, Bradke F. Systemic administration of Epothilone D improves functional recovery of walking after rat spinal cord contusion injury. Exp Neurol. 2018;306:243-9. https://doi.org/10.1016/j.expneurol.2017.12.001.

33. Hofstetter CP, Holmstrom NA, Lilja JA, et al. Allodynia limits the usefulness of intraspinal neural stem cell grafts; directed differentiation improves outcome. Nat Neurosci. 2005;8(3):346-53. https://doi.org/10.1038/nn1405.

34. Sandner B, Puttagunta R, Motsch M, Bradke F, Ruschel J, Blesch A, et al. Systemic Epothilone D improves hindlimb function after spinal cord contusion injury in rats. Exp Neurol. 2018;306:250-9. https://doi.org/10.1016/ j.expneurol.2018.01.018.

35. Brizuela M, Blizzard CA, Chuckowree JA, Dawkins E, Gasperini RJ, Young KM, et al. The microtubule-stabilizing drug Epothilone $D$ increases axonal sprouting following transection injury in vitro [in English]. Mol Cell Neurosci. 2015;66(Pt B):129-40. https://doi.org/10.1016/j.mcn.2015.02.006.

36. Yousefifard M, Rahimi-Movaghar V, Nasirinezhad F, Baikpour M, Safari S, Saadat $\mathrm{S}$, et al. Neural stem/progenitor cell transplantation for spinal cord injury treatment; a systematic review and meta-analysis [in English] Neuroscience. 2016;322:377-97. https://doi.org/10.1016/j.neuroscience.2016. 02.034 .

37. Xiong Y, Zeng YS, Zeng CG, du BL, He LM, Quan DP, et al. Synaptic transmission of neural stem cells seeded in 3-dimensional PLGA scaffolds. Biomaterials. 2009;30(22):3711-22. https://doi.org/10.1016/..biomaterials.2009. 03.046 .

38. Jin $\mathrm{H}$, Zhang $Y T$, Yang $Y$, Wen $L Y$, Wang $J H$, Xu HY, et al. Electroacupuncture facilitates the integration of neural stem cell-derived neural network with transected rat spinal cord. Stem Cell Reports. 2019;12(2):274-89. https://doi. org/10.1016/j.stemcr.2018.12.015

39. Li X, Liu SM, Zhao YN, Li J, Ding W, Han S, et al. Training neural stem cells on functional collagen scaffolds for severe spinal cord injury repair [in English]. Adv Funct Mater. 2016;26(32):5835-47. https://doi.org/10.1002/a dfm.201601521.

40. Courtine G, Sofroniew MV. Spinal cord repair: advances in biology and technology. Nat Med. 2019;25(6):898-908. https://doi.org/10.1038/s41591-01 9-0475-6.

41. Anderson MA, Burda JE, Ren Y, Ao Y, O'Shea TM, Kawaguchi R, et al. Astrocyte scar formation aids central nervous system axon regeneration. Nature. 2016:532(7598):195-200. https://doi.org/10.1038/nature17623.

42. Anderson MA, O'Shea TM, Burda JE, Ao Y, Barlatey SL, Bernstein AM, et al. Required growth facilitators propel axon regeneration across complete spinal cord injury. Nature. 2018;561(7723):396-400. https://doi.org/10.1038/ s41586-018-0467-6.

43. Lin $H$, Chen B, Wang B, Zhao Y, Sun W, Dai J. Novel nerve guidance material prepared from bovine aponeurosis. J Biomed Mater Res A. 2006;79(3):591-8. https://doi.org/10.1002/jbm.a.30862

44. Li X, Han J, Zhao YN, Ding W, Wei J, Li J, et al. Functionalized collagen scaffold implantation and cAMP administration collectively facilitate spinal cord regeneration [in English]. Acta Biomater. 2016;30:233-45. https://doi. org/10.1016/.actbio.2015.11.023.

45. Han S, Xiao Z, Li X, Zhao H, Wang B, Qiu Z, et al. Human placenta-derived mesenchymal stem cells loaded on linear ordered collagen scaffold improves functional recovery after completely transected spinal cord injury in canine. Sci China Life Sci. 2018;61(1):2-13. https://doi.org/10.1007/s11427016-9002-6.

\section{Publisher's Note}

Springer Nature remains neutral with regard to jurisdictional claims in published maps and institutional affiliations.

Ready to submit your research? Choose BMC and benefit from:

- fast, convenient online submission

- thorough peer review by experienced researchers in your field

- rapid publication on acceptance

- support for research data, including large and complex data types

- gold Open Access which fosters wider collaboration and increased citations

- maximum visibility for your research: over $100 \mathrm{M}$ website views per year

At $\mathrm{BMC}$, research is always in progress.

Learn more biomedcentral.com/submissions 